\title{
Nietzsche: génesis y validez de la moral
}

\author{
ENRIQUE SERRANO GÓMEZ \\ Departamento de Filosofía \\ Universidad Autónoma Metropolitana-Iztapalapa \\ eserranog@aol.com
}

\begin{abstract}
Resumen: Si bien en la mayoría de las interpretaciones se afirma que Nietzsche a través de su método genealógico cuestiona la validez universal de los principios morales, cuando se examinan con cuidado sus argumentos se aprecia que el problema es más complejo. Para empezar, Nietzsche sostiene, mediante una variante de lo que se conoce hoy en día como explicación de mano invisible, que la moral es un artificio. Este carácter artificial es precisamente lo que explica la diversidad de morales que encontramos en la historia. Luego cuestiona radicalmente la denominada eticidad de las costumbres; es decir, aquel tipo de moral tradicional que identifica la buena acción con el respeto a las normas establecidas. Pero esta crítica presupone, como él mismo lo reconoce, un criterio de validez que no puede reducirse a la dimensión histórica. Se trata, en este trabajo, de reconstruir de manera crítica dicho criterio de validez.
\end{abstract}

Palabras clave: historia, explicaciones de mano invisible, justicia, razón

\begin{abstract}
Many interpretations of Nietzsche's philosophy claim that his genealogical method challenges the universal validity of moral principles. Yet, when one scrutinizes his arguments in more detail, a much more complex problem is revealed. In the first place, we find Nietzsche ascertaining, through a quite distinctive use of so-called invisible-hand explanations, that morals is an artifice; this artificial character explaining away the diversity of customs in history. Secondly, we find that, despite Nietzsche's radical criticism of morality, this very criticism relies on a certain criterion of validity, which cannot be reduced to the historical dimension, as he himself acknowledges. This paper critically interprets the latter criterion of validity.
\end{abstract}

Key words: history, invisible-hand explanations, justice, reason

El destino de una época cultural que ha probado el fruto del árbol del conocimiento es tener que saber que no podemos deducir el sentido de los acontecimientos mundiales del resultado de su estudio, por muy completo que éste sea. Por el contrario, debemos ser capaces de crearlo por nosotros mismos. También tiene que saber que los ideales nunca pueden ser el producto de un saber empírico progresivo. Y, por lo tanto, que los ideales supremos que más nos conmueven sólo se manifiestan en todo tiempo gracias a la lucha con otros ideales, los cuales son tan sagrados como los nuestros.

MAX WEBER

En el comienzo de la filosofía moderna se cuestionó radicalmente la creencia tradicional en la existencia de un orden (cósmico, divino, natural) que otorga un sentido objetivo a los fenómenos empíricos. Uno de los efectos de esta crítica fue percibir el devenir histórico como la expresión del carácter irracional de las acciones humanas. Se asumió la existencia de un 
abismo insuperable entre razón e historia, pues mientras los atributos de la primera son la universalidad y la necesidad, los atributos de los acontecimientos históricos son la particularidad y la contingencia. De acuerdo con esta concepción, la única manera de acceder al conocimiento del mundo social es trascender la temporalidad para describir la naturaleza humana, esto es, la esencia inmutable de este peculiar ente. Sin embargo, después de innumerables intentos de ofrecer una descripción del ser humano con validez universal, se advirtió que la naturaleza humana es la cultura, es decir, una realidad histórica y, por tanto, variable. Precisamente la prueba empírica de la contingencia del mundo humano, así como de la flexibilidad del ser que lo habita, se encuentra en la pluralidad percibida en los distintos contextos sociales e históricos.

Posteriormente, los representantes de la Ilustración destacaron que situar la historia más allá del ámbito de la razón es una contradicción, pues ello equivale a negar la universalidad con que se distingue. La universalidad propia de la razón implica la pretensión de explicar todo fenómeno (Nihil est sine ratione), por lo que también debe ser posible encontrar la rosa de la razón en el devenir histórico. El recurso que utilizó la Ilustración para establecer un vínculo entre razón e historia (para dar razón de la historia) fue apelar a la noción de progreso. Si bien la noción de progreso representa una secularización de la tradicional noción judeocristiana de perfeccionamiento, entre ambas existe una diferencia fundamental: mientras que la noción tradicional de perfeccionamiento implica un parámetro trascendente, la noción de progreso busca explicar en términos inmanentes. Por eso es que el desarrollo tecnológico, propiciado por la revolución industrial, se convierte en la base empírica del concepto de progreso, aunque desde un principio se asume el supuesto de que ese desarrollo tecnológico se encuentra entrelazado con la formación moral y política de la humanidad. ${ }^{1}$

El siglo XIX puede ser calificado como el siglo de la Historia, pues durante él adquirió carta de ciudadanía en la república de las ciencias; sin embargo, desde que se admitió el carácter científico de la historia, el concepto de progreso quedó sometido a las exigencias del escrutinio científico, lo cual ocasionó que pronto surgieran dudas sobre su validez. Uno de los efectos de la crítica a la creencia en el progreso, que sostenían las filosofías de la historia, fue la consolidación de la tesis respecto de que la racionalidad no se encuentra en el devenir histórico en sí, sino únicamente en los métodos de investigación del acontecer histórico. Sin embargo, la consecuencia más importante del desarrollo de la ciencia histórica consistió en poner en duda la pretensión universalista de la razón. Si el proyecto ilustrado era hacer patente el sentido racional del devenir histórico, ahora

\footnotetext{
${ }^{1}$ Lo que se cuestionará en el siglo xx es este hipotético nexo entre desarrollo técnico y formación moral.
} 
el vínculo entre razón e historia conducía a la transformación de la primera en un hecho histórico más. Junto con el historicismo, Friedrich Nietzsche es un representante de esta posición teórica.

En la filosofía de Nietzsche, la genealogía se utiliza como un instrumento para disolver la pretensión de validez universal propia de la razón. Si bien su primer objetivo es la moral, ya que se trata de hacer patente que los contenidos de la distinción entre el bien y el mal son variables, su objetivo último es demostrar que todo conocimiento es resultado de una perspectiva particular, la cual se define por un sistema de valores ligados a una posición concreta. Nietzsche arremete contra el núcleo de la noción tradicional de la racionalidad, a saber, el concepto de verdad.

¿Qué es entonces la verdad? Una hueste en movimiento de metáforas, metonimias, antropomorfismos, en resumidas cuentas, una suma de relaciones humanas que han sido realzadas, extrapoladas y adornadas poética y retóricamente y que, después de un prolongado uso, un pueblo considera firmes, canónicas y vinculantes; las verdades son ilusiones que se han vuelto gastadas y sin fuerza sensible, monedas que han perdido su troquelado y no son ahora ya consideradas monedas, sino metal. (Nietzsche 1990, p. 25)

Nietzsche cuestiona el añejo prejuicio de que nuestro conocimiento es el reflejo de la realidad estructurada u ordenada en sí misma. Desde su punto de vista, el conocimiento es un artificio que responde a las necesidades cambiantes de los individuos. El sistema de conceptos creados por la razón tiene como función generar un orden que permita a los seres humanos adaptarse a un medio hostil. Nietzsche extrae las últimas consecuencias de la llamada revolución copernicana que realiza la filosofía moderna. Su posición extrema se define por negar la existencia de una verdad absoluta, ya que toda verdad es relativa a un sistema de conceptos que depende, a su vez, de lo que él mismo denomina un sistema de utilidades, esto es, un conjunto de valores particulares, vigentes en una sociedad, los cuales hacen posible seleccionar y organizar los datos empíricos. ${ }^{2}$ Para ofrecer una explicación más amplia de esta tesis central en la que se sustenta la estrategia genealógica, se reconstruirán algunos aspectos de la segunda consideración intempestiva, titulada Sobre la utilidad y el prejuicio de la historia para la vida (1873).

\footnotetext{
${ }^{2}$ Weber sabe aprovechar esta tesis nietzscheana en su teoría de los tipos ideales. Éstos representan modelos que nos permiten aproximarnos a la complejidad de lo real y son construidos siempre a partir de un interés teórico específico. La llamada Wertfreiheit no es negar la presencia de valores en el proceso de conocimiento; por el contrario, se trata de asumir que todo modelo teórico se construye a partir de ciertos valores que hacen posible crear un sentido para organizar la experiencia. Saber esto da la libertad de moverse entre diferentes tipos ideales e incluso entre distintas teorías generales.
} 


\section{Perspectiva y saber histórico}

Esta consideración intempestiva se inicia con la siguiente observación de Goethe: "Por cierto, aborrezco todo lo que se limita a instruirme sin aumentar o vigorizar mi actividad." En contra de aquellos que abogan por convertir la historia en una ciencia, y en oposición también a las filosofías de la historia con pretensiones de absoluto, Nietzsche sostiene que el primer criterio para juzgar las narraciones históricas no es la verdad, sino la utilidad para la vida. El sentido histórico es propio del ser humano, en cuanto que es un animal que ha desarrollado el lenguaje como medio de supervivencia y, con él, la capacidad de almacenar la experiencia. Sin embargo, aunque la memoria puede ser útil para la vida, también puede degenerar y atrofiar la voluntad de poder humana. En contra de la creencia en el saber histórico como un valor incuestionable, se advierte que es "posible vivir y aun vivir felizmente casi sin recordar, como lo vemos en el animal; pero es imposible vivir sin olvidar". Sólo aquel que pueda situarse en el presente, olvidando en gran parte el pasado, podrá superar el vértigo y el miedo que produce el devenir y, de esta manera, crear las condiciones para acceder a la felicidad.

A pesar de las sugerentes observaciones psicológicas y morales, el peso de su argumento tiene un carácter estrictamente epistemológico. La tesis que sustenta la argumentación destaca que la realidad histórica se caracteriza ante todo por una enorme complejidad. Ninguna narración histórica puede abarcar esa complejidad; en todos los casos se introduce un conjunto de valores que hacen posible seleccionar y organizar los datos históricos. De esta manera, se cuestiona radicalmente el ideal de una teoría que pueda reproducir el sentido del devenir histórico. De hecho, el sentido no es un dato, sino la creación de un narrador desde su presente. De ahí que la historia pueda y deba ser escrita constantemente. Por otra parte, resulta imposible pensar en una gran narración capaz de abarcar todas las demás, ya que entre los valores y sus jerarquías existen contradicciones. Quizá sea demasiado afirmar que las narraciones son inconmensurables, pero, por lo menos, sí son irreductibles a una gran metanarración.

Esta tesis se encuentra ya en la Crítica del juicio, de Kant, donde se afirma que la teleología es el instrumento del juicio reflexionante para organizar la diversidad de los datos empíricos. Es decir, el principio teleológico no tiene un carácter ontológico, como sucede en la filosofía de Aristóteles, sino que representa un recurso que el sujeto introduce en la reflexión de lo real. El propio Kant advierte que no se puede afirmar con certeza si la humanidad progresa. Es posible narrar la historia como un progreso de la libertad que, gracias al desarrollo tecnológico, abre nuevas posibilidades a los seres humanos; pero también es posible narrarla como un proceso de decadencia, basados en el incremento del potencial destructivo de la humanidad. Estas dos narraciones son verdaderas en la medida en que pueden sustentarse 
con una gran cantidad de material empírico seleccionado según el sentido que las guía. Por eso no se trata de preguntar cuál de ellas es la verdadera (dicha pregunta no es legítima), sino cuál de ellas puede resultar más útil para los propósitos de los seres humanos. Kant nos propone pensar como si la humanidad progresara, para poder aprovechar las oportunidades del futuro, pero asumiendo que en este campo no puede haber certezas, porque todo depende de las acciones de los individuos y éstas son libres.

Sin embargo, Nietzsche no considera que la finalidad objetiva, denominada así por Kant, sea la única útil para reflexionar sobre el devenir histórico. Por el contrario, para Nietzsche la nombrada finalidad sin fin, propia de la estética, resulta más adecuada. Situar el sentido de la historia en un fin ubicado en un futuro lejano lleva a considerar los diferentes momentos históricos como simples etapas o medios para alcanzarlo. Al igual que los románticos, a Nietzsche le interesa resaltar la peculiaridad e importancia de cada momento histórico. En Humano, demasiado humano se afirma:

Los frutos según la estación. Todo futuro mejor que se le desee a la humanidad es necesariamente también un futuro peor en más de un respecto, pues es una quimera creer que una nueva etapa superior de la humanidad reunirá en sí todas las ventajas de etapas anteriores y que deba, por ejemplo, producir también la suprema configuración del arte. Más bien cada estación tiene sus atractivos y encantos para sí y excluye los de las otras. (Nietzsche 2001b, $\S 239)$

Ningún progreso es absoluto, ya que todo avance implica costos. Todo progreso lo es con relación a un punto de vista o a un fin particular. ${ }^{3}$ Una vez elegido un fin específico, se puede hablar de un progreso, en la medida en que se establecen los medios más adecuados para acceder a él. Pero no existe un fin supremo que nos permita sostener la presencia de un progreso de la humanidad en general. En cuanto se asume la pluralidad de fines, es posible percibir que los avances en un campo pueden tener costos en otro, y como cada uno de los campos de la acción humana tiene sus propios fines y valores, no es posible establecer una balance unívoco u objetivo. Lo que un grupo puede estar dispuesto a sacrificar para llegar a una meta, otro grupo lo puede ver como una renuncia inaceptable.

Una vez que Nietzsche reconoce que el conocimiento histórico, como todo conocimiento, no es independiente de los valores que guían las acciones, distingue tres tipos de interés que motivan la aproximación a la historia: 1) perseguir un motivo; 2) preservar y venerar lo que se ha hecho, y 3) liberarse. A estos tres intereses, ligados al sentido histórico de

3 "El uso legítimo del concepto de progreso en nuestras disciplinas está ligado siempre al aspecto técnico, esto es, al medio apropiado para un fin dado unívocamente. Nunca se eleva a la esfera de las valoraciones últimas" (Weber 1984, p. 99). 
los seres humanos, corresponden tres tipos de historia: 1) la monumental; 2) la anticuaria, y 3) la crítica. Cada una tiene su utilidad para la vida, pero también están sujetas a una deformación que lleva a la atrofia de la voluntad de poder.

La historia monumental ofrece imágenes de la grandeza pasada para que sirvan de ejemplo a los hombres del presente. "Su consigna es que aquello que una vez fue capaz de agrandar el concepto de humano y llenarlo de un contenido más bello tiene que existir siempre, para ser capaz de realizar eso eternamente" (Nietzsche 1989, p. 26). La historia monumental rechaza la demanda de "veracidad plena" (volle Wahrhaftigkeit) porque su objetivo es recuperar la excelencia humana, para que ésta sea eterna, en la medida en que los individuos poderosos la realicen en los diversos contextos históricos. Pero la historia monumental en manos de los débiles tiene un efecto nocivo para la vida. Los débiles no usan las imágenes de la grandeza del pasado como ejemplos para emular, sino que las utilizan como ídolos para adorar. Ídolos que sirven como máscaras para ocultar su odio a los poderosos de su tiempo. Su lema es: "dejad a los muertos que entierren a los vivos".

Por su parte, la historia anticuaria ofrece a los individuos y a las comunidades la posibilidad de obtener una identidad que les sirva para vivir en su presente. "Este sentido anticuario de veneración del pasado tiene su valor más alto, cuando infunde un sentimiento simple y conmovedor a la realidad modesta, ruda y hasta penosa en que vive un individuo o un pueblo" (Nietzsche 1989, p. 36). Sin embargo, la historia anticuaria degenera en el momento mismo en que ya no se encuentra animada por la fresca vida del presente. La historia anticuaria se convierte en el refugio de aquel individuo que, por miedo de enfrentar el futuro, se convierte en un erudito. Éste no digiere la información, sino que la convierte en una armadura que si bien oculta su debilidad, también le impide moverse.

La historia crítica sirve como antídoto contra la degeneración de los otros tipos de historia, porque su misión es romper y disolver el pasado que, habiendo sido sacralizado, por ello se ha convertido en un peso muerto que impide la innovación propia de la dinámica vital. Su consigna es: "todo lo que nace merece perecer; sería, pues, mejor que nada naciese". $\mathrm{Su}$ forma de operar es buscar aquello que los otros tipos de historia han dejado a un lado. Si la historia monumental y la historia anticuaria se interesan por lo grande y lo venerable, respectivamente, la historia crítica descubre sin piedad la violencia, la debilidad, la corrupción, los errores; en fin, todas aquellas atrocidades ligadas por siempre a las acciones humanas. El gran peligro de la historia crítica es que el horror que devela paralice a los seres humanos, los desmoralice y, de esta manera, les impida actuar, condenándolos al nihilismo del ocaso. 
Todo individuo y todo pueblo requiere una dosis variable de historia, según sean sus objetivos, sus fuerzas y sus necesidades, en la que se mezclen estos diferentes tipos de intereses históricos. Las consecuencias de no encontrar la cantidad y la combinación adecuada para cada situación son la decadencia y la muerte. Precisamente, la motivación que subyace al escrito Sobre la utilidad y el perjuicio de la historia para la vida es desarrollar un diagnóstico de su contexto. Para Nietzsche, en las sociedades modernas del siglo XIX existe un exceso de historia que asfixia la vida.

En cinco aspectos me parece que el exceso de historia en una época puede ser peligroso y hostil a la vida: En primer lugar, tal exceso provoca la oposición entre lo interno y lo externo [...] y debilita así la personalidad; en segundo lugar, hace que una época se imagine que posee la más rara de las virtudes, la justicia, en grado superior a cualquier otra época; por otra parte, perturba los instintos del pueblo e impide que llegue a la madurez, tanto el individuo como el conjunto de la sociedad; también implanta la creencia, siempre nociva, en la vejez de la humanidad, la creencia de ser fruto tardío y epígono; finalmente, induce a una época a caer en el peligroso estado de ánimo de la ironía respecto a sí misma y, de ahí, a la acritud todavía más peligrosa del cinismo. Con esta última actitud, una época evoluciona más y más en la dirección de un practicismo calculador y egoísta que paraliza y, por último, destruye las fuerzas vitales. (Nietzsche 1989, p. 54)

Para curar la enfermedad histórica (el exceso de historia que ha atacado la fuerza plástica de la vida), Nietzsche recomienda un fuerte remedio compuesto de lo ahistórico y lo suprahistórico. Por lo ahistórico entiende la capacidad de poder olvidar, para centrarse en un horizonte limitado; es decir, se trata de proponerse un fin, haciendo a un lado el exceso de información, lo cual facilita la adquisición del poder para realizarlo. Lo suprahistórico, por su parte, define la fuerza para apartar la mirada del devenir y dirigirla a lo eterno, esto es, el arte y la religión, en cuanto que estos productos culturales representan la capacidad humana de crear formas duraderas: "La suprema voluntad de poder es imprimir (aufzuprägen) el carácter del Ser en el devenir" (Nietzsche 1980, § 617). Pero esa eternidad que se le atribuye al Ser es una ilusión que hace posible actuar, superando el vértigo del devenir. Así es con todas las grandes cosas, "nunca se logran sin una ilusión", como lo afirma Hans Sachs en Los maestros cantores.

Nietzsche no niega la importancia del sentido histórico ni de la ciencia histórica. Su crítica se dirige a una visión de la historia que, al operar sin freno, cierra las posibilidades del futuro, puesto que destruye las ilusiones. Este sentido de la historia desmedido es propio de una concepción de la ciencia que convierte la verdad y la objetividad en fetiches, al olvidar que todo conocimiento presupone valores ligados a una perspectiva particular. Para Nietzsche, la propensión fundamental del ser humano no es la 
búsqueda del saber, sino la búsqueda del poder, entendido como medio para acrecentar la vida. Incluso, su estrategia crítica, su forma de hacer filosofía con el martillo, consiste en un saber histórico, el cual, sin embargo, se asume como un saber al servicio de los intereses vitales. Se trata de contemplar el devenir histórico, así como todos los horrores que en él acontecen, pero sin perder la fuerza que otorga la ilusoria búsqueda de lo eterno. " "Mi tesis puede, pues, ser así entendida y ponderada: Tan sólo las personalidades fuertes pueden soportar la historia; los débiles son barridos por ella" (Nietzsche 1989, p. 59). El sentido histórico que no cae en el vértigo del devenir, sino que extrae del pasado el material que debe ser fundido para construir los cimientos del futuro, es la llamada genealogía.

\section{La genealogía como estrategia crítica}

La forma es fluida, pero el sentido lo es todavía más.

NiETZSCHE

Nietzsche introduce el término genealogía en la filosofía para referirse a un modo de hacer historia que consiste, en primer lugar, en una mezcla de lo que él llamó historia crítica e historia monumental. Se trata de recuperar aquello que las historias monumentales clásicas y las eruditas olvidan, con el objetivo de hacer ver que lo considerado por estas narraciones como el origen es, en realidad, el resultado de un proceso histórico. Dicho con otras palabras, el objetivo es desnaturalizar las creencias dominantes, mostrando, además, que lo considerado como eterno y sagrado no es más que un efecto de acontecimientos que prefieren olvidarse, porque se encuentran ligados a la violencia y a la dominación. ${ }^{5}$ La función de la historia monumental en la genealogía consiste en obtener la fuerza para no paralizarse ante los horrores históricos, actualizando aquellos ejemplos de excelencia humana que también encontramos en el pasado y con los cuales pueda forjarse un ideal para adentrarse en la región incierta del futuro. ${ }^{6}$

${ }^{4}$ Se trata de un saber histórico con carácter político (la gran política), en la acepción que, más tarde, definiría con más precisión Max Weber: se trata de luchar una y otra vez por lo imposible, para alcanzar, por lo menos, lo posible.

${ }^{5}$ Con la terminología de Weber se puede afirmar que se trata de cuestionar la validez de las formas de legitimación tradicionales, que son las más abundantes en la historia de la humanidad. Se trata de un tipo de legitimación que considera que algo es válido porque así se hace y se ha hecho desde siempre.

${ }^{6}$ Peter Berkowitz acierta cuando afirma: "Al presentar su examen de la genealogía en Nietzsche, la genealogía, la historia, declara Foucault: 'La genealogía es gris meticulosa y pacientemente documental.' Sin embargo, la inspiradora descripción que pasa a hacer del genealogista un erudito ejemplar es una tontería. Si la genealogía consiste en la esmerada recogida de un vasto material de fuentes y en la paciente atención al detalle como dice Foucault, entonces Nietzsche no es ningún genealogista" (Berkowitz 1995, pp. 97-98). 
El propio Nietzsche advierte que el antecedente de la genealogía se encuentra en el método de aquellos que él denomina los psicólogos ingleses, método que le es próximo debido al libro de Paul Rée El origen de los sentimientos morales [Der Ursprung der moralischen Empfindungen (1877)]. El modelo más cercano a la propuesta de Nietzsche se encuentra en la llamada historia natural de Hume y, en especial, la historia teórica o conjetural de Adam Smith. Este último nunca se propone hacer una cronología de los acontecimientos del pasado; su objetivo es partir de la realidad de las sociedades en el presente para posteriormente reconstruir la posible lógica que se ha seguido hasta llegar a ellas. Se trata de ofrecer una narración verosímil del camino que va de las sociedades rudas a las sociedades modernas o civilizadas. ${ }^{7}$ La historia conjetural, como la genealogía, no se basa en una descripción, sino en una definición de los pasos que se han dado para llegar a un punto determinado.

Nietzsche simpatiza con el método de los psicólogos ingleses, el cual los lleva a buscar el origen de la moral en el traspatio de la historia, desde donde es posible percibir el lado oscuro de la humanidad. Sin embargo, afirma que ellos también carecen de espíritu histórico, ya que en sus disquisiciones sostienen que es la alabanza de quienes se benefician de las acciones no egoístas lo que lleva a identificar a estas últimas con lo bueno. Pero con ello se asume que la antítesis egoísta-no egoísta, surgida del espíritu de rebaño, está dada desde siempre, y, así, se naturaliza el prejuicio de que lo moral es equivalente a las acciones desinteresadas, no egoístas. En oposición a esta tesis, Nietzsche afirma: "Antes bien, sólo cuando los juicios aristocráticos de valor declinan es cuando la antítesis egoísta-no egoísta se impone cada vez más a la conciencia humana" (Nietzsche 1989, p. 79). Pero la crítica no se limita a esta tesis defendida por Paul Reé, sino que se extiende a la posición más frecuente de la tradición inglesa, representada por Herbert Spencer, quien sostiene que el concepto bueno es esencialmente idéntico al concepto útil o conveniente. Aunque Nietzsche reconoce que esta segunda tesis es más fuerte, en cuanto que "resulta psicológicamente sostenible", hace notar que cae en el mismo error de la anterior, a saber, olvidar que el sentido es fluido y que, por tanto, también el concepto de utilidad o conveniencia es variable en los distintos contextos históricos.

La crítica a esta segunda tesis (la más extendida e importante) de los psicólogos ingleses nos permite descifrar el objetivo central de la estrategia genealógica. Se trata de atacar un viejo dogma, que si bien tiene sus orígenes en las metafísicas de Platón y Aristóteles, ha tenido mayor vigencia.

\footnotetext{
${ }^{7}$ Esta propuesta también influyó en los escritos de filosofía de la historia de Kant. Por otra parte, la presencia de Adam Smith en la filosofía de Nietzsche se hará todavía más notoria cuando remita a la relación entre acreedor y deudor como raíz de la moral. Precisamente, Smith entiende la moral como un artificio sustentado en el intercambio (no necesariamente mercantil).
} 
Ese dogma representa uno de los pilares de la metafísica sustancialista, hegemónica en la historia de la filosofía, y puede ser descrito mediante el siguiente argumento: la forma de cada objeto define su función y se encuentra dada por naturaleza; es decir, la forma representa la sustancia, aquello que es invariable. Por lo que se puede concluir que cada objeto tiene una función por naturaleza, lo que hace posible definir de manera universal la utilidad de cada cosa. En contra de esto, Nietzsche sostiene que la forma y la función de los objetos deben disociarse, ya que la función depende de un sentido, el cual es la expresión de una voluntad de poder particular. Dicho de otra manera, cada objeto puede cumplir con diferentes funciones, dependiendo del sistema de finalidades por el que es utilizado. Ese sistema de finalidades depende a su vez de una manera de valorar, la cual varía en los distintos contextos sociales e históricos.

Pero todas las finalidades, todas las utilidades son sólo indicios de que una voluntad de poder se ha enseñoreado de algo menos poderoso y ha impreso en ello, partiendo de sí misma, el sentido de una función; y la historia entera de una cosa, de un órgano, de un uso, puede ser así una ininterrumpida cadena indicativa de interpretaciones y reajustes siempre nuevos, cuyas causas no tienen siquiera necesidad de estar relacionadas entre sí, antes bien a veces se suceden y relevan de un modo meramente causal. El desarrollo de una cosa, de un uso, de un órgano es, según esto, cualquier cosa antes que su progressus hacia una meta, y menos aún un progreso lógico y brevísimo, conseguido con el mínimo gasto de fuerza y de costes, sino la sucesión de procesos de avasallamiento más o menos profundos, más o menos independientes entre sí, que tienen lugar en la cosa, a la que hay que añadir las resistencias utilizadas en cada caso para contrarrestarlos, las metamorfosis intentadas con una finalidad de defensa y de reacción, así como los resultados de contraacciones afortunadas. (Nietzsche 1981, § 12, pp. 88-89)

A partir de la teoría de la evolución desarrollada por Darwin, Nietzsche asume la idea de que las formas propias de los organismos son el resultado de una evolución, por lo que no es posible aceptar que representan una sustancia ajena al devenir. Pero si las formas son fluidas, el sentido que define la función lo es todavía más. Tanto forma como función son resultados no predeterminados de fuerzas en oposición dentro de un proceso de adaptación. La necesidad de cambio de las formas en el mundo orgánico corresponde a la necesidad de transformación del sentido en el mundo cultural. La estrategia crítica de la genealogía consiste, precisamente, en disolver las sustancias en el río del devenir. Todo aquello que se considera eterno, esto es, una forma, un sentido, un principio, etcétera, se muestra como el efecto contingente de una historia. Además, a diferencia de sus predecesores ingleses, Nietzsche niega que entre los sentidos se pueda establecer la existencia de un progreso. La historia aparece, desde su punto 
de vista, como una sucesión de formas y sentidos que expresan un mecanismo ciego, en el que se da un juego de fuerzas carente de sentido y fin.

Si gran parte de las filosofías tradicionales se propusieron encontrar un fundamento a la moral, Nietzsche rechaza la existencia de algún tipo de fundamento. Para él, la llamada fundamentación de la moral no es otra cosa que la creencia candorosa en la validez de la moral dominante en un contexto determinado. Según él, sería importante realizar un tipo de historia erudita que recogiera una gran cantidad de material histórico sobre la pluralidad de sentidos, esto es, de valoraciones o puntos de vista de apreciación, para después ofrecer una tipología de las morales. Sin embargo, él mismo no realiza esta labor historiográfica. Su estrategia crítica pretende ser más radical y mostrar que la propia moral, independientemente de su sentido particular, no es un fenómeno originario, sino el resultado de un proceso social. Es decir, para Nietzsche, los seres humanos no son por naturaleza morales. La moral representa, según su punto de vista, un artificio social cuyas variaciones de sentido denotan las transformaciones de los poderes reinantes en la sociedad.

Para lograr su propósito, Nietzsche debe mostrar que la moral surge de una realidad no moral. No se trata de hacer una cronología de cómo apareció efectivamente la moral en la historia, es decir, la genealogía de la moral no es una narración histórica ni, menos todavía, una historia erudita. La genealogía busca reconstruir la lógica de la aparición de la moral, determinando las condiciones necesarias para que este fenómeno surja y estableciendo una concatenación entre éstas. Lo que encontramos en La genealogía de la moral es algo muy cercano a lo que se ha llamado recientemente una explicación de mano invisible, en la que se muestra la producción de un fenómeno mediante un proceso donde confluyen las acciones de una pluralidad de individuos, los cuales son impulsados por motivos egoístas y, por ello, no prevén ni intentan generar el fin de dicho proceso. El término mano invisible no es muy afortunado, porque puede crear la confusión de apelar a una sabiduría superior, a una astucia de la razón, que opera a las espaldas de los individuos; cuando en realidad se refiere a un proceso no intencional, donde el azar (la conjunción fortuita de diversas variables), así como continuos reajustes, desempeñan un papel importante. ${ }^{8}$ Esta modalidad de explicaciones puede representarse mediante el siguiente esquema:

\section{(1) $Y$ es un efecto de $X$.}

\footnotetext{
${ }^{8}$ Como es bien sabido, el precursor de este tipo de explicaciones es Adam Smith; pero lo que generalmente se ignora es que este autor no sólo las utiliza para dar cuenta de la dinámica del mercado, sino que también, y en primer lugar, para explicar la constitución de la normatividad social a través de una historia (conjetural) de los sentimientos sociales. Para Adam Smith, el mercado no puede funcionar como un mecanismo de mano invisible mientras no exista en la sociedad una infraestructura moral y, en especial, un conjunto de instituciones que garanticen los principios de justicia.
} 
(2) $Z$ es un conjunto de individuos con una historia común.

(3) $V$ es una ventaja o efecto positivo que genera $Y$ en $Z$.

(4) $Y$ no es un producto intencionado.

(5) La relación causal entre $X$ y $Y$ no es conocida por los actores.

(6) $W$ es el conjunto de los esfuerzos aislados y egoístas de los miembros de $Z$ a lo largo de su historia común.

(7) $X$ es un efecto colectivo y sistemático de $W{ }^{9}$

Lo que distingue a Nietzsche de otros autores que utilizan esta modalidad de explicaciones es la interpretación que ofrece de la noción de ventaja $(V)$ utilizada en la premisa (3). Generalmente se interpreta esa ventaja en términos colectivos; en este caso, que la moral representa un elemento útil para el grupo, pues permite, por ejemplo, la persistencia del orden social que hace posible la convivencia. Esta idea de un bien colectivo al que deben subordinarse los individuos es lo que cuestiona Nietzsche. Para él, la utilidad que proporciona la moral tiene que pensarse en términos individuales y, para ser más precisos, en términos del incremento de la voluntad de poder de los individuos, es decir, de su felicidad.

La tesis de Nietzsche, como veremos, consiste en afirmar que la moralidad representa una condición necesaria para formar individuos soberanos, señores de la voluntad libre, a los cuales es lícito hacer promesas, ya que a través de sus acciones tienen cierto control del futuro. Este fruto supremo de la cultura se logra cuando el individuo rompe con los prejuicios de la que él denomina eticidad de la costumbre (Sittlichkeit der Sitte) y, con la misma fuerza que usa para esa destrucción, construye una moral propicia para la vida. Aunque se reconozca la validez de la crítica de Nietzsche a las morales que exigen el sacrificio de los individuos para alcanzar un bien superior, cabe advertir que esa ventaja individual no se opone necesariamente a una ventaja colectiva. Precisamente lo que se encuentra en juego en la reflexión ética es la posible coordinación entre el bien del individuo (la felicidad) y el bien colectivo (la justicia). La demanda de justicia no se opone a la búsqueda individual de la felicidad; lo que implica la primera son límites a esta última para que todos puedan poner en práctica su proyecto de vida buena. La capacidad de hacer promesas y, por tanto, de autolimitarse, es lo que distingue a la moral de los individuos soberanos, cuyo ideal central es convertir la vida social en una coexistencia de señores de la voluntad libre. Pero antes de desarrollar esta crítica a la moral individualista de Nietzsche,

\footnotetext{
${ }^{9}$ Las explicaciones de mano invisible son una variante de las explicaciones funcionalistas, aunque presuponen otra problemática. Sobre esto, véase Vanberg 1999.
} 
utilizando sus propios términos, es preciso comprobar que el esquema explicativo que se ha enunciado es aplicable a su posición teórica, por lo que veamos cómo plantea la genealogía de la conciencia moral.

\section{La genealogía de la conciencia moral}

En el primer tratado de La genealogía de la moral, después de plantear su crítica a los psicólogos ingleses, sostiene que el método adecuado para determinar el sentido originario de bueno es el análisis etimológico. De acuerdo con este método, según él, ${ }^{10}$ se encuentra que el concepto bueno en diversas lenguas remite a las cualidades propias de aquello que es considerado noble y aristocrático, mientras que malo remite a lo vulgar, a lo plebeyo. El adjetivo bueno representaría, en un principio, la autodesignación de los poderosos en su relación con un grupo de individuos menos poderosos. "El pathos de la nobleza y de la distancia, como hemos dicho, el duradero y dominante sentimiento global y radical de una especie superior dominadora en su relación con una especie inferior, con un abajo -éste es el origen de la antítesis bueno y malo" (Nietzsche 1978, I, § 2). En este caso, lo bueno no se opone a egoísta; por el contrario, lo bueno sería la expresión de una voluntad que se afirma y que toma distancia de lo otro, aquello que no es ella misma, lo cual es visto como lo malo (schlecht), entendido como lo débil. En contraste con esta forma primaria de valorar, en las morales predominantes en la modernidad lo bueno se identifica con lo débil, con el sujeto pasivo y mediocre, mientras que lo malvado (böse) se identifica con la persona que ejerce libremente su voluntad de poder.

Es decir, desde la perspectiva de Nietzsche, en la historia de la cultura occidental se ha dado una transvaloración (Umvertung): lo que antes era considerado bueno se valora como lo malvado, mientras que lo malo se ha transformado en lo bueno. Los dos sistemas de valores contrapuestos (bueno-malo, bueno-malvado), según él, habrían librado una lucha terrible en la que dominaría la segunda manera de valorar; victoria propiciada en gran parte por el cristianismo. Una vez establecida esta transvaloración como un hecho histórico, el objetivo es explicar cómo surgió. Para eso se introduce la hipótesis de la aparición de una división en la originaria casta de los nobles, la cual da lugar a una contraposición entre la casta de los guerreros y la casta de los sacerdotes. Esta última representa una casta

\footnotetext{
${ }^{10}$ Sin ser un experto en filología, me parece que la estrategia argumentativa de Nietzsche es bastante débil en este punto; por ejemplo, un análisis histórico y antropológico le hubiera permitido fundamentar de una manera más sólida esta premisa. En casi todas las culturas, bueno es el adjetivo que se utiliza para calificar los atributos de la identidad propia, mientras que lo malo denota lo otro, aquello que no es uno mismo; incluso, en muchos casos, el concepto de ser humano se utiliza para hablar del grupo al que se pertenece. Esta forma de diferenciar entre lo bueno y lo malo está ligada al acto mismo de valorar.
} 
intermedia, pues si bien es parte de la nobleza y, por tanto, es un grupo diferenciado de la masa de esclavos, su poder no es suficiente para vencer a la casta de los guerreros en una lucha abierta: "ilas cosas les van muy mal cuando aparece la guerra!" A causa de esta impotencia, el odio crece en ellos, hasta convertirse en algo monstruoso y siniestro.

El odio reprimido de la casta sacerdotal se convierte en el resentimiento, y éste se vuelve una fuerza creadora que engendra la segunda manera de valorar (bueno $=$ débil, malvado $=$ fuerte). Esta nueva moral, donde mentirosamente la debilidad se ha convertido en mérito, es utilizada por los sacerdotes para sublevar a los esclavos contra los nobles. La moral se convierte en un instrumento de venganza que le permite a la casta sacerdotal tomar el poder.

Mientras que el ser humano noble vive con confianza y franqueza frente a sí mismo [...], el ser humano del resentimiento no es franco, ni ingenuo, ni honesto y derecho consigo mismo. Su alma mira de reojo; su espíritu ama los escondrijos, los caminos tortuosos y las puertas falsas, todo lo encubierto le atrae como su mundo, su seguridad, su alivio; entiende de callar, de no olvidar, de aguardar, de empequeñecerse y humillarse transitoriamente. Una raza de humanos del resentimiento acabará necesariamente por ser más inteligente que cualquier raza noble, venerará también la inteligencia en una medida del todo distinta, a saber: como la más importante condición de existencia; mientras que, entre hombres nobles, la inteligencia fácilmente tiene un delicado dejo de lujo y refinamiento. (Nietzsche 1978, I, § 10)

Además de la evidente crítica a la moral tradicional, lo primero que se puede extraer de la descripción del proceso de transvaloración es el fundamento de la tesis enunciada en Más allá del bien y del mal: "No existen fenómenos morales, sino una interpretación moral de los fenómenos" (Nietzsche 1978, § 186). En efecto, la pluralidad de formas de valorar indica que los valores no son cualidades de los fenómenos en sí, sino elementos que introducen los sujetos en su relación con el mundo. La diversidad de valores representa las distintas perspectivas de los individuos, que remiten, a su vez, a diversas posiciones dentro de la sociedad, así como a distintos contextos sociales e históricos. Por ello, Nietzsche afirma que todos los sistemas de valoración son ilusiones, en el sentido de ser creaciones del sujeto; también habla de que se trata de mentiras, en tanto que ningún valor implica la noción de adecuación, propia de la verdad.

Sin embargo, es preciso destacar que a pesar de caracterizar los sistemas de valores como ilusiones o mentiras, Nietzsche asume, de manera implícita, la posibilidad de evaluar esos sistemas. Así, reconoce que si bien la manera noble de valorar se equivoca, no envenena; es decir, no atenta contra la vida, como lo hace el resentimiento contenido, característico de la moral de los esclavos. No obstante, al mismo tiempo reconoce que el modo 
de valorar de los sacerdotes, que impregna la moral de los esclavos, ha convertido al ser humano en un animal profundo e interesante, capaz de generar el mundo cultural ("La historia humana sería una cosa demasiado estúpida sin el espíritu que los impotentes han introducido en ella" (Nietzsche 1978, I, § 7). Nietzsche no pretende tener una visión del mundo ajena a los valores; toda su reflexión filosófica pretende destacar que la valoración de los fenómenos es una tendencia espontánea e insuperable de los seres humanos (por más que se trate de disimular, como en determinadas concepciones de la ciencia) que precede a la búsqueda de descripciones verdaderas. ${ }^{11}$ Por eso, el tema del segundo tratado es la relación de esta propensión humana a valorar con el desarrollo de la conciencia moral.

Para explicar la génesis de la conciencia moral se requiere, en primer lugar, establecer cómo el ser humano se convirtió en un animal al que le es lícito hacer promesas; capacidad que representa la base para el cumplimiento de los deberes morales. Es obvio que la institución social de la promesa presupone la memoria. Contra la posición dominante en la psicología de su tiempo, para Nietzsche el olvido no representa el fenómeno de una conciencia debilitada, sino la tendencia espontánea de todo ser viviente. El olvido, como hemos señalado ya, es un elemento necesario de la vida, una fuerza que la hace posible. Por eso, lo que se requiere explicar es cómo los seres humanos adquieren una memoria que les permite cumplir sus promesas. La respuesta de Nietzsche a esta interrogante es clara: la memoria se forma gracias al dolor y, en especial, al dolor infligido por otros individuos en la forma de castigo o pena. "Para que algo permanezca en la memoria se lo graba a fuego; sólo lo que no cesa de doler permanece en la memoria -éste es un axioma de la psicología más antigua [...]. Cuando el ser humano consideró necesario hacerse una memoria, tal cosa no se realizó jamás sin sangre, martirios, sacrificios" (Nietzsche 1981, II, § 3).

Una vez establecido este vínculo entre dolor y memoria, se busca explicar la génesis de la mala conciencia, la "planta más extraña e interesante de toda nuestra vegetación terrestre", la cual constituye el ingrediente fundamental de la moral tradicional. Nietzsche se remite a la relación entre acreedor y deudor, entendida como una especie de protocontrato que hace posible el intercambio. Cuando esta relación deja de ser un mero intercambio directo y se convierte en préstamo, el deudor, para infundir confianza en su promesa de restitución, empeña un bien que posee, como puede ser su cuerpo, su mujer, su libertad o incluso su vida. Lo importante es que la lógica de esta forma de compensación resulta muy extraña, ya que se establece una equivalencia entre la pérdida que puede sufrir el acreedor y el sufrimiento que éste puede infligir al deudor. Dicha equivalencia implica

11 "Acaso todavía nuestra palabra alemana humano (Mensch, manas) exprese precisamente algo de ese sentimiento de sí; el humano se designaba como el ser que mide valores, que valora y mide, como el animal tasador en sí" (Nietzsche 1981, II, § 8). 
que el permiso de ejecutar un castigo doloroso al otro genera un placer que puede servir de compensación. "Ver sufrir produce bienestar; hacer sufrir más bienestar todavía, ésta es una tesis dura, pero es un axioma antiguo, poderoso, humano, demasiado humano" (Nietzsche 1981, II, § 6). Una prueba empírica del placer que produce ver y hacer sufrir se encuentra en que, para casi todas las culturas, un elemento importante de sus festividades es el espectáculo del sufrimiento.

Es tal el placer que produce el sufrimiento del otro, que si no se controlan estas licencias para infligir un castigo ni la crueldad de los acreedores, pronto se desataría una violencia generalizada que impediría la vida social. Por eso Nietzsche considera como un paso fundamental de este proceso la aparición de individuos poderosos, fundadores de Estados, que se erigieron como mediadores entre los acreedores y los deudores. La formación de poderes encargados de administrar la justicia representó el gran paso civilizador; estos poderes debían tener la suficiente fuerza para controlar los instintos violentos de sus súbditos. El proceso civilizador se encuentra ligado en todos los casos a una relación de dominio; el sometimiento al poder político y eclesiástico es el factor fundamental en la crianza de ese animal con memoria, al que le es lícito hacer promesas.

Históricamente considerado, el derecho representa en la tierra [...] la lucha precisamente contra los sentimientos reactivos, la guerra contra éstos realizada por poderes activos y agresivos, los cuales empleaban parte de su fortaleza en imponer freno y medida al desbordamiento del pathos reactivo y en obligar por la violencia a un compromiso [...]. De acuerdo con esto, sólo a partir del establecimiento de la ley existen lo justo y lo injusto [...]. Hablar en sí de lo injusto es algo que carece de todo sentido; en sí ofender, violentar, despojar, aniquilar no pueden ser naturalmente injustos desde el momento en que la vida actúa esencialmente, es decir, en sus funciones básicas, ofendiendo, violando, despojando, aniquilando, y no se la puede pensar en absoluto sin ese carácter (Nietzsche 1981, II, § 11).

En este punto, la relación entre acreedor y deudor deja de ser un nexo entre individuos para convertirse en el vínculo entre el individuo como deudor y el orden social, producido por los poderosos como representantes del acreedor. Conforme aumenta el poder del orden social, es posible introducir un grado de benevolencia mayor ante las infracciones que cometen sus miembros. Podemos decir que el poder de la comunidad es inversamente proporcional a la severidad del derecho penal (aunque esto no es una ley que se cumpla de manera inefable). La humanización del derecho penal es un síntoma de que se ha tenido éxito en la domesticación de los seres humanos, gracias a un prolongado y doloroso proceso histórico.

Nietzsche también utiliza la relación entre acreedor y deudor para dar cuenta de la aparición de los dioses, que, con la consolidación de la moral 
de los esclavos, se tornarán en uno solo (monoteísmo). En el interior de la comunidad familiar reina el convencimiento de que la estirpe subsiste gracias a los sacrificios de los antepasados, por lo que esta deuda debe pagarse con tributos y honores. Los antepasados sobreviven como espíritus poderosos de quienes son deudores todos los miembros de la familia. El temor y la deuda aumenta, según esta lógica, conforme el poder de la estirpe se incrementa hasta que los antepasados acaban por ser transfigurados en dioses. De esta manera encontramos que conforme se desarrolla la dinámica de la deuda en los distintos campos de la sociedad, el individuo se ve sometido a los diversos poderes sociales y su voluntad de poder ha sido domesticada. Nietzsche introduce en este punto la hipótesis más importante del segundo tratado de La genealogía de la moral, la que se refiere al origen de la mala conciencia:

Yo considero que la mala conciencia es la profunda dolencia a que tenía que sucumbir el hombre bajo la presión de aquella modificación, la más radical de todas las experimentadas por él, de aquella modificación ocurrida cuando el hombre se encontró definitivamente encerrado en el sortilegio de la sociedad y de la paz. (Nietzsche 1981, II, § 16)

En una situación social donde los instintos violentos del individuo no pueden desahogarse hacia fuera, se tornan hacia dentro (interiorización), para formar lo que más tarde se denominó su alma. Conforme fue creciendo la represión y, con ella, la inhibición de esas pasiones activas, el alma, el mundo interior del individuo, fue adquiriendo profundidad, anchura, hasta formar la mala conciencia. Es la mala conciencia, surgida del sufrimiento del ser humano infligido por sí mismo, la que valora las acciones no egoístas como lo bueno, y de esta manera se establecen las condiciones para el desarrollo de la moral tradicional, aquella que somete a los individuos a la opresora estrechez y regularidad de las costumbres. De ahí que Nietzsche denomine eticidad de las costumbres a los sistemas normativos que han regido a las sociedades durante miles de años, en los cuales se exige una obediencia ciega a los mandatos implícitos en las tradiciones sociales.

Si bien Nietzsche califica la mala conciencia de fenómeno patológico surgido de la interiorización de los instintos violentos, al mismo tiempo considera que representa la posibilidad de acceder al nivel del individuo soberano, del individuo igual sólo a sí mismo, del individuo autónomo situado por encima de la eticidad, aquel ser humano que se hace responsable de sus acciones. "Es una enfermedad la mala conciencia, no hay duda, pero una enfermedad como lo es el embarazo" (Nietzsche 1981, II, § 19). En efecto, someter durante siglos a los individuos a la rigidez de las costumbres creó las condiciones para dar a luz al señor de la voluntad libre, aquel que posee en sí mismo la medida de su valor y que, por tanto, se convierte 
en un creador de nuevas formas de vida en las que ya no rigen los ideales hostiles a la vida.

Si volvemos al esquema de las explicaciones de mano invisible, podemos darle ahora el siguiente contenido:

(1) La mala conciencia $(Y)$ es un efecto de la represión social, legitimada en la conciencia de la deuda $(X)$;

(2) en un grupo de individuos sometidos históricamente a la eticidad de las costumbres $(Z)$,

(3) la mala conciencia proporciona a los individuos una ventaja $(V)$, ya que ella es la condición necesaria para que se subleven y conquisten la soberanía que les permita convertirse en creadores de valores;

(4) la mala conciencia $(Y)$ es un producto no intencional, generado por una larga historia de represión y dominación;

(5) la relación causal entre represión $(X)$ y mala conciencia $(Y)$ no era conocida por los individuos;

(6) a lo largo de la historia se mantienen los esfuerzos aislados y egoístas $(W)$ de los miembros de $Z$, y

(7) la represión social $(X)$, legitimada en la conciencia de la deuda, representa el efecto colectivo y sistemático de los esfuerzos aislados y egoístas de los seres humanos $(W)$.

Nietzsche sustenta en esta explicación genealógica la tesis de que la identificación entre "bueno" y acciones no egoístas, propia de la moral de las costumbres, es un artificio social, generado por un proceso no intencional de domesticación de los seres humanos. Ello también apoya la tesis del primer tratado, respecto de que lo que se valoraba originalmente como bueno era el egoísmo; valoración propia de la moral aristocrática. Sin embargo, el individuo soberano del que se habla en el segundo tratado de La genealogía de la moral no implica una simple vuelta a la moral aristocrática original.

\section{4. ¿Genealogía en oposición a validez universal?}

Tanto Nietzsche, en diversos pasajes de sus obras, como gran parte de sus intérpretes consideran que el análisis genealógico derrumba la pretensión de validez universal de la razón; pero confunden dos niveles que deben diferenciarse. Antes de entrar al tema de la moral, para distinguir entre el nivel de la génesis y el de la validez, podemos acudir a un tema que aparece en el apartado 17 del segundo tratado de La genealogía de la moral. Ahí se afirma que el Estado apareció históricamente como una horrible tiranía, 
como una maquinaria trituradora y desconsiderada; ello lleva a concluir: "Yo pienso que así queda refutada aquella fantasía que le hacía comenzar con un contrato." Si bien es cierto que la inmensa mayoría de los Estados han surgido a partir de la violencia y la dominación, este hecho histórico no invalida el planteamiento de las teorías del contrato. En estas últimas no se busca ofrecer una explicación de la genealogía del Estado, sino determinar las condiciones que deben cumplirse para que el poder estatal adquiera una legitimación racional. La argumentación de las teorías del contrato social no es histórica; de hecho, ellas no miran al pasado, sino al futuro: se trata de establecer la estructura y los procedimientos necesarios para que el Estado deje de ser un simple instrumento de dominio.

La diferenciación entre génesis y validez nos remite a dos usos de la razón, el teórico y el práctico, los que, a su vez, denotan dos perspectivas distintas: la del espectador y la del participante. Cuando se pregunta por la génesis de un fenómeno, se asume la perspectiva del espectador (teórica) para describir la historia o el proceso hipotético que llevó a su constitución. En cambio, la pregunta por la validez tiene que ver con el interés del participante por establecer un criterio racional para juzgar su fines. Al cuestionar la validez de la moral, no se trata de hacer una historia de las morales que han imperado en los distintos contextos sociales e históricos, ni tampoco reducir la pluralidad a un sistema único. El objetivo de tal interrogación es determinar un criterio formal que nos permita analizar críticamente el contenido de esas morales históricas. Cabe destacar que esta distinción también se encuentra, de manera implícita, en el proyecto filosófico de Nietzsche. Para poder ver esta doble perspectiva se requiere precisar, en primer lugar, qué entiende este autor por moral; es decir, establecer con claridad cuál es el objeto de su crítica. Para ello podemos remitirnos al libro con el que "empieza su campaña contra la moral": Aurora. En el parágrafo 9 de dicho libro se afirma:

Aquí, por ejemplo, tenemos una tesis principal: La moralidad no es otra cosa (por consiguiente, nada más) que la obediencia a las costumbres, cualesquiera que éstas sean; pero las costumbres no son sino la forma convencional de evaluar y actuar. Allí donde no manda la tradición no existe la moralidad; y cuanto menos esté determinada la vida por la tradición, más estrecho será el radio de acción de la moralidad. El hombre libre es inmoral, porque quiere depender en todo de sí mismo y no de una tradición. Así, en todos los estados primitivos de la humanidad, el calificativo malvado significa lo mismo que libre, individual, arbitrario, desacostumbrado, imprevisto e impredecible.

Más adelante, en el parágrafo 19 se agrega:

Las costumbres representan las experiencias adquiridas por los hombres anteriores con respecto a lo que consideraban útil o nocivo - pero el sentimiento 
con respecto a las costumbres (la moralidad) no hace referencia ya a estas experiencias como tales, sino a la antigüedad, la santidad y el carácter incuestionable de las costumbres. Por ello, la moralidad se opone a que se realicen nuevas experiencias y a corregir las costumbres, esto es, se opone a la formación de nuevas y mejores costumbres, es decir, embrutece.

Esta identificación de la moral con las tradiciones o las costumbres establecidas no es exclusiva de Aurora, se encuentra en toda su obra; por ejemplo, en Humano, demasiado humano (2001b [1878]) se decía: "Ser moral, decente, ético, significa prestar obediencia a una ley o tradición de antiguo fundada" ( $\S 96$ ). De acuerdo con esto, el objeto de la crítica no es la moral en general, sino una comprensión particular de la moral, la cual, aunque sea la más extendida espacial y temporalmente, no deja de ser una comprensión deficiente, pues la antigüedad y la vigencia de una norma moral no pueden identificarse con su validez racional. De hecho, muchos filósofos anteriores a Nietzsche realizaron una crítica a esta comprensión de la moralidad; incluso se puede decir que la crítica a lo que el autor de La genealogía de la moral denomina eticidad de la costumbre es un rasgo de la reflexión ética moderna.

La sospecha fundada de Nietzsche es que la eticidad de la costumbre representa un atentado contra la búsqueda de la felicidad individual, al tratar de imponer a los seres humanos modelos generales de vida buena. "El ser humano moral más moral es el que se sacrifica la mayoría de la veces a la costumbre [...]. El individuo debe sacrificarse -así lo exige la eticidad de la costumbre" (Nietzsche 2000, § 9). Los ideales ascéticos de la eticidad de la costumbre son los corsés y las camisas de fuerza utilizados para domesticar a los individuos y, de esta manera, someterlos a un sistema de utilidades definido por la forma de dominación vigente. Una vez establecido el objeto de la crítica, el siguiente paso es determinar el criterio en el que se sustenta.

En contra de las exigencias de la eticidad de la costumbre, Nietzsche afirma que el criterio de validez moral se encuentra en la vida, entendida como un proceso de renovación permanente, en el cual se abren siempre nuevas perspectivas. Ello quiere decir que la validez de la moral es la autonomía del individuo que le permite crear valores en la definición de su propia forma de vida buena. Nietzsche percibe con claridad que la felicidad no es un ideal de la razón, sino de la imaginación y que, por tanto, la búsqueda de esa felicidad depende de la capacidad inventiva de los individuos. Ninguna moral puede imponer o exigir que se cumpla una forma de vida particular. La razón puede auxiliar al individuo en el proceso de autoconocimiento, así como en la definición de los medios más adecuados para acceder a los fines que se propone; pero la definición del contenido que se da al fin último de la felicidad tiene que ser una creación individual. 
Ahora bien, aunque Nietzsche se opone radicalmente al tradicionalismo y a la rigidez de la eticidad de la costumbre, al mismo tiempo reconoce que ella representa una condición necesaria para forjar lentamente al individuo soberano, al superhombre, capaz de vivir de acuerdo con los valores que él mismo crea y, por tanto, capaz de asumir la responsabilidad de sus acciones. El ingente trabajo de la eticidad de la costumbre, con todo el sufrimiento, la tiranía y la estupidez que implica, tiene su justificación en el fruto maduro de su árbol: el individuo soberano.

Ese ser humano del futuro, que nos liberará del ideal existente hasta ahora y asimismo de lo que tuvo que nacer de él, de la gran náusea, de la voluntad de la nada, del nihilismo. Ese toque de campana del mediodía y de la gran decisión, que de nuevo libera la voluntad, que devuelve a la tierra su meta y al ser humano su esperanza, ese anticristo y antinihilista, ese vencedor de Dios y de la nada —alguna vez tiene que llegar... (Nietzsche 1981, II, § 24)

De acuerdo con esto, las variaciones, las transvaloraciones y el pluralismo que encontramos en el análisis genealógico de la moral no implican negar un criterio de validez universal para juzgar el contenido diverso de las morales. Dicho de otra manera, la diversidad que se aprecia en la historia no niega necesariamente la pretensión de establecer un criterio de validez universal. En este punto, el propio Nietzsche asume la distinción entre génesis y validez, así como la existencia de un criterio universal en el que se fundamenta la moral: la vida.

La pregunta por el origen de nuestras valoraciones morales y de nuestras tablas de bienes no coincide exactamente con su crítica, como se ha creído muchas veces, si bien es cierto que adentrarse en una pudenda origo produce en consecuencia para el sentimiento un descrédito de la cosa originada y organiza contra la misma una disposición de ánimo y una actitud críticas. ¿Qué valor merecen nuestras valoraciones morales, nuestras tablas de bienes? ¿Qué es lo que en realidad ganamos con su sostenimiento? ¿Quién lo gana? ¿En relación con qué? La respuesta no puede ser otra cosa que la vida. (Nietzsche 1980, p. 254)

Este texto es fundamental, pues Nietzsche reconoce que el análisis genealógico, con todas las aportaciones posibles, no suprime el problema de la validez. Entonces, lo que se tiene que discutir ahora es la noción de vida como criterio de validez de las normas morales. Como se ha mencionado, en la filosofía nietzscheana, decir que la vida representa el criterio de validez para juzgar la moral implica sostener que la moral debe ser útil para el desarrollo de las capacidades del individuo en la búsqueda de la felicidad. Al igual que Kant, Nietzsche asume que la definición del contenido de la felicidad y de los medios para alcanzarla debe ser realizada por el individuo de manera autónoma. Sin embargo, a diferencia de Kant, esa autonomía 
no se vincula, por lo menos en primera instancia, con la razón, sino con la voluntad de poder. En contraste con el utilitarismo y con el propio Kant, para Nietzsche el objetivo supremo de la moral tiene que ser la felicidad individual. Con ello pasa por alto que el concepto de bien moral encierra dos determinaciones: la felicidad y la justicia. El problema central de la ética consiste precisamente en conjugar la felicidad con la justicia, entendida esta última como aquellos principios que hacen posible la convivencia social.

La espontaneidad vital, considerada como una situación en que los individuos no encuentran ninguna restricción al ejercicio de su voluntad de poder, conduce a un estado de naturaleza como lo describe Hobbes, esto es, a una guerra de todos contra todos en la cual, si bien en un principio los más fuertes pueden imponerse, a largo plazo nadie puede ser feliz. Como el mismo Hobbes advirtió, la fuerza individual es relativa; hasta el individuo más poderoso se encuentra inseguro en esa situación caótica. Por tanto, aunque se asuma que la moral no puede ir en contra de la vitalidad y la capacidad creadora del individuo, se tiene que reconocer que ello no es suficiente para definir un criterio de validez moral. El propio Nietzsche sostiene, como se ha destacado, que el individuo soberano no es un producto espontáneo o natural, sino que representa el fruto del trabajo del ser humano sobre sí mismo, realizado durante un largo proceso de aprendizaje histórico. Entre otras cosas, esto implica que en el criterio para juzgar moralmente las acciones no sólo se debe tener en cuenta la defensa de la vida en abstracto, sino también la defensa de la vida propiamente humana, para la cual es imprescindible la constitución de un orden civil y el desarrollo de la cultura. Estos elementos sólo son posibles si se apela a un principio universal de justicia. Antes de sacar alguna conclusión apresurada, veamos qué nos puede decir la filosofía moral nietzscheana sobre el tema de la justicia.

Sin duda, la perspectiva genealógica permite superar los prejuicios de la eticidad de la costumbre; aquellos que convierten la moral en un obstáculo para la búsqueda de la felicidad individual. Sin embargo, el método genealógico no ofrece una alternativa para enfrentar el problema de conjugar la felicidad individual y la justicia. Nietzsche admite que la vida en abstracto no es justa, pues en su dinámica espontánea no existe ninguna garantía contra el despojo, la violación y el aniquilamiento.

Hay que admitir incluso algo todavía más grave: que, desde el punto de vista biológico, a las situaciones de derecho no les es lícito ser nunca más que situaciones de excepción, que constituyen restricciones parciales de la auténtica voluntad de vida, la cual tiende hacia el poder y que están subordinadas a la finalidad global de aquella voluntad como medios particulares, es decir, como medios para crear unidades mayores de poder. (Nietzsche 1981, II, § 11) 
Esto da lugar a una interpretación para la cual el tema de la justicia en la moral nietzscheana no tiene un papel primario, y que se podría sustentar en numerosos textos. Sin embargo, sin negar la ambigüedad que existe en ella, me parece que la reflexión de Nietzsche es más compleja.

Para Nietzsche, al igual que para Hume, la justicia es una virtud artificial. Ello quiere decir que, contra el iusnaturalismo tradicional, no existe un orden objetivo (natural o divino) de cuyo conocimiento se puedan extraer los principios que deben regular las relaciones sociales. Las normas de justicia son creación de los individuos a través de una larga historia de confrontaciones. La cuestión es saber si se puede establecer un criterio para analizar las normas de justicia que se generan en la dinámica social.

La justicia (equidad) se origina entre personas más o menos igualmente poderosas, como acertadamente lo comprendió Tucídides (en el terrible diálogo entre los emisarios atenienses y melios); allí donde no hay poder dominante claramente reconocible y una lucha revertiría en un inútil prejuicio recíproco, brota la idea de entenderse y ponerse de acuerdo sobre las pretensiones de ambos bandos: el carácter inicial de la justicia es el carácter de trueque. Cada cual da satisfacción al otro, en tanto que cada cual recibe lo que valora más que el otro. Se le da a cada uno lo que en adelante quiere tener como suyo, y se recibe a cambio lo deseado. La justicia es por tanto retribución y trueque bajo el supuesto de un poderío más o menos igual [...]. La justicia se reduce naturalmente al punto de vista de una autoconservación sagaz, por tanto al egoísmo de aquella reflexión ¿para qué perjudicarme inútilmente y quizá no alcanzar sin embargo mi meta? (Nietzsche 2001b, § 92). ${ }^{12}$

En este texto se ofrece una perspectiva genealógica de la justicia, pero de ella se puede extraer un criterio de justicia que la trasciende. Resulta verosímil la tesis de que la justicia nace del entendimiento o acuerdo entre personas que poseen un poder más o menos igual. En el caso que narra Tucídides en su Historia de la guerra del Peloponeso (libro V, 85-116), los atenienses, al tener mucho más poder que los melios, pudieron imponer sus condiciones, por lo que éstas no pueden considerarse justas. El grado de igualdad de poder es una forma (quizá no suficiente) de garantizar que el acuerdo no es resultado de una imposición o una manipulación, sino de un acto voluntario de las partes. Por otro lado, también resulta verosímil la tesis de que en su origen histórico (filogénesis), pero igualmente en la socialización de los individuos (ontogénesis), el motivo que impulsa la creación y aceptación de principios de justicia es un interés egoísta, sagaz

12 "La justicia, en este primer nivel, es la buena voluntad, entre hombres de poder aproximadamente igual, de ponerse de acuerdo entre sí, de volver a entenderse mediante un compromiso - y, con relación a los menos poderosos, de forzar a un compromiso a esos hombres situados por debajo de uno mismo" (Nietzsche 1981, II, § 8). 
o reflexivo. Un individuo sagaz puede percibir que respetar unos principios de justicia en sus relaciones con personas tan poderosas como él, le permite eludir riesgos y prejuicios.

Pero, una vez aceptada esta perspectiva genealógica, podemos ir más allá, con el objetivo de establecer un criterio de justicia universal; que no es otro que el añejo principio: Volenti non fit iniura, es decir, ahí donde existe un acuerdo voluntario, libre, no puede existir injusticia. Este principio no define el contenido concreto de las normas de justicia que deben regir en una sociedad; su función es ofrecer un criterio racional para examinar dichas normas. Además, vinculado a este principio de justicia universal se encuentra un principio que define lo que podemos denominar el punto de vista moral, el cual se ha expresado de diversas maneras a lo largo de la historia: "No hagas a otro lo que no quisieras que te hiciesen a ti", "Actúa de tal manera que la máxima de tu acción se convierta en ley universal", "No hagas mal a nadie, antes bien ayuda a quien puedas", "Entre los individuos como entre las naciones, el respeto al derecho ajeno es la paz", etcétera. Sin duda, entre estas expresiones del principio moral existen grandes diferencias, pero todas ellas comparten la exigencia del reconocimiento del otro como persona, reconocimiento que muestra ser un requisito para alcanzar un consenso en torno a las normas que permiten coordinar las acciones de todos los participantes. El reconocimiento recíproco de los participantes, aunado al mencionado principio de justicia universal, conforma el hoti (qué) o núcleo universal de la moral.

La multiplicidad de morales que encontramos en la historia coinciden en este contenido mínimo; lo que varía en ellas son los valores ligados a las distintas formas de vida particular, así como la amplitud del reconocimiento intersubjetivo. Mientras la moral de los nobles, de la que se habla en $L a$ genealogía de la moral, implica un reconocimiento restringido, las luchas sociales que se han desarrollado a lo largo de la historia hasta nuestros días han conducido a su ampliación. La formación moral de la humanidad no es inventar nuevos contenidos, sino el proceso de incorporación de la pluralidad humana, lo cual lleva a diferenciar el núcleo universal de la moral de la multiplicidad de formas de vida particulares. Sin embargo, Nietzsche no advirtió que esta ampliación del reconocimiento recíproco de los individuos, propiciado por la exigencia universal de la razón, no conduce necesariamente ni a una eticidad de la costumbre ni a una moral del rebaño. Por el contrario, al ir ampliándose paulatinamente el reconocimiento, resulta imposible tratar de negar la pluralidad humana, lo cual conduce al individuo a enfrentar ineludiblemente el politeísmo conflictivo de los valores. En las sociedades modernas se pierde la seguridad que otorgan las tradiciones, lo que genera las condiciones para que los seres humanos se vean obligados a crear sus propios modelos de vida buena. Lo que se pierde en seguridad se gana en libertad. 
Precisamente el individuo soberano, el superhombre, es aquel que puede situar la prioridad en la libertad sin sentir nostalgia por las certezas que ofrecen las costumbres vigentes. Nietzsche acierta cuando destaca la ambivalencia del nihilismo propio de las sociedades modernas. Por una parte, la pérdida de la eticidad de la costumbre produce desorientación y una debilitación de la voluntad de poder (nihilismo del ocaso); pero, por la otra, también motiva la capacidad creadora de los individuos para la búsqueda de nuevas perspectivas y fines (nihilismo de la aurora). A pesar de ello, Nietzsche pasó por alto que el conflicto fundamental de las sociedades modernas, ante el resquebrajamiento de los diques que representan las tradiciones, consiste en la falta de coordinación entre las formas de vida particulares y los principios de justicia universal que hacen posible la convivencia social.

Este déficit de la filosofía moral de Nietzsche se hace patente en la falta de comprensión de la complejidad que encierra el valor de la igualdad. Para él, la igualdad es un valor de la moral de los esclavos con el que se pretende negar las diferencias de poder de los individuos y, con ello, reprimir a los seres humanos capaces de abrir nuevas perspectivas. De ahí sus ataques al ideal democrático y socialista de la igualdad. Nietzsche comparte con Spinoza la tesis: Unusquisque tantum juris habet, quantum potentia valet (El derecho que posee cada uno es proporcional al poder que tiene). Esta tesis puede ser aceptada desde un punto de vista genealógico o histórico; pero, desde la perspectiva de la validez racional, lo que se exige es que los derechos de los individuos sean independientes de su poder. Aparentemente esta última exigencia, ligada a un principio de justicia, entra en contradicción con la posición individualista y aristocrática que él defiende. Por eso, a pesar de que Nietzsche reconoce la importancia de la justicia para la convivencia social, en última instancia tiende a inclinarse a favor del individualismo que hemos detectado en su explicación genealógica de la moral.

Sin embargo, ello es un error, porque los valores aristocráticos e individualistas no se contraponen necesariamente al principio de igualdad inherente a la justicia. El ideal aristocrático que defiende Nietzsche no tiene nada que ver con la noción tradicional de una aristocracia, cuyos privilegios se basan en el nacimiento. Como ya lo advertía Maquiavelo en su crítica a la monarquía hereditaria, no existe ninguna garantía de que el hijo del príncipe conquistador tenga el mismo poder que su padre. Me parece que existe un amplio consenso respecto de que lo defendido por Nietzsche es la aristocracia en su sentido etimológico; esto es, el gobierno de los mejores: aquellos que tienen la capacidad de crear valores y abrir nuevas perspectivas. Si esto es así, se requiere un orden social justo, que permita a los mejores destacar, con independencia de su procedencia social. La realización del ideal aristocrático vitalista que propone Nietzsche 
tiene como condición necesaria que impere en la sociedad una igualdad de condiciones, pues de lo contrario se cae ineludiblemente en la aristocracia basada en la tradición, propia de las sociedades anquilosadas que atentan contra la renovación y la diversidad de la vida. Ahora bien, si queremos encontrar una determinación más concreta de las condiciones que hacen posible conjugar la libertad individual con la justicia, tenemos que ir más allá de la filosofía moral de Nietzsche.

\section{BIBLIOGRAFÍA}

Beltrán, Julio, 1994, "Conjeturas nietzscheanas sobre el comienzo de la civilización”, Diánoia, año XL, no. 40, pp. 189-212.

Berkowitz, Peter, 1995, Nietzsche. La ética de un inmoralista, trad. María Condor, Cátedra, Madrid.

Decher, Friedhelm, 1984, Wille zum Leben-Wille zur Macht, Königshausen und Neumann, Würzburg.

Deleuze, Gilles, 1971, Nietzsche y la filosofía, trad. Carmen Artal, Anagrama, Barcelona.

Elster, Jon, 1995, Ulises y las sirenas, trad. Juan José Utrilla, Fondo de Cultura Económica, México.

Habermas, Jürgen, 1982, Sobre Nietzsche y otros ensayos, trad. Carmen García Trevijano y Silverio Cerra, Tecnos, Madrid.

Jaspers, Karl, 1981, Nietzsche, Walter de Gruyter, Berlín.

Nietzsche, Friedrich, 2001a, Ecce homo, trad. Andrés Sánchez Pascual, Alianza, Madrid.

—_ 2001b (1878), Humano, demasiado humano, trad. Alfredo Brotóns, Akal, Madrid.

——, 2000, Aurora, trad. Germán Cano, Biblioteca Nueva, Madrid.

_ _ 1990, "Sobre verdad y mentira en sentido extramoral", en F. Nietzsche y Hans Vaihinger, trad. Luis M. Valdés y Teresa Orduña, Sobre verdad y mentira, Tecnos, Madrid.

__ 1989 (1873), Vom Nutzen und Nachteil der Historie für das Leben, Insel, Fráncfort. [Versión en castellano: Sobre la utilidad y el perjuicio de la historia para la vida, trad. Germán Cano, Biblioteca Nueva, 1999.]

—_, 1981, La genealogía de la moral, trad. Andrés Sánchez Pascual, Alianza, Madrid.

—_, 1980, Der Wille zur Macht, Kröner, Stuttgart.

—_ 1978, Más allá del bien y del mal, trad. Andrés Sánchez Pascual, Alianza, Madrid.

—_, 1971, Werke, Stauffacher, Fráncfort, 3 vols.

Salaquarda, Jörg (comp.), 1980, Nietzsche, Wissenschaftliche Buchgesellschaft, Darmstadt.

Stegmaier, Werner, 1994, Nietzsches Genealogie der Moral, Wissenschaftliche Buchgesellschaft, Darmstadt.

Tanner, Michael, 1994, Nietzsche, Herder, Friburgo. 
Vanberg, Viktor, 1999, Racionalidad y reglas, trad. Ernesto Garzón Valdés, Gedisa, Barcelona.

Weber, Max, 1984, "Los juicios de valor en la ciencia social", La acción social: ensayos metodológicos, trad. Michael Faber-Laiser y Salvador Giner, Península, Barcelona.

Recibido el 24 de octubre de 2003; revisado el 26 de marzo de 2004; aceptado el 29 de marzo de 2004. 